\title{
Adaptif Komşuluk Seçimi ve Ăğırlık Atama Yöntemleri ile Hiperspektral Görüntülerin Sınıflandırılması
}

\author{
Tuğcan DÜNDAR ${ }^{1 *}$, Taner İNCE ${ }^{2}$ \\ ${ }^{1}$ Gaziantep Üniversitesi, Mühendislik Fakültesi, Elektrik ve Elektronik Mühendisliği Bölümü, Gaziantep \\ (dundar@gantep.edu.tr) ORCID ID 0000 -0003 - 1374 - 8651 \\ ${ }^{2}$ Gaziantep Üniversitesi, Mühendislik Fakültesi, Elektrik ve Elektronik Mühendisliği Bölümü, Gaziantep \\ (tanerince@gantep.edu.tr) ORCID ID 0000 - 0003 - 1757 - 5209
}

\begin{abstract}
Öz
Seyrek gösterim tabanlı teknikler sağladıkları performans nedeniyle sinyal ve görüntü işleme, bilgisayarlı görme ve örüntü tanıma gibi alanlarda araştırmacılar tarafından sıklıkla kullanılmaktadır. Son zamanlarda hiperspektral görüntülerin sınıflandırılması ile ilgili önerilen metotlarda da seyrek gösterim teknikleri kullanılmış ve olumlu sonuçlar elde edilmiştir. Bu makalede, adaptif komşuluk seçimi ile ağırlık atama yöntemlerini birlikte kullanan bir ortak seyrek gösterim tabanlı sınıflandırıcı önerilmektedir. İlk olarak, test pikseli etrafında oluşturulan sabit boyutlu pencere içerisindeki piksellerin tümünün sınıflandırma işlemine dahil edilmesi yerine test pikseline yakın mesafedeki ve benzer spektral karakteristiğe sahip pikseller seçilerek sinıflandırmaya dahil edilmiştir. Bu sayede test pikseline uzak mesafedeki ve spektral olarak benzemeyen komşu pikseller ayrılmıştır. Daha sonra test pikselinin sınıf etiketini belirlerken hesaplanması gereken artık değerde seyrek katsayı matrisi her bir sınıf için belirlenen ağırlıklarla çarpılmıştır. Ağırlıklar belirlenirken seçilen pikseller ile her bir sınıfa ait eğitim sözlüğü arasındaki benzerlik dikkate alınmıştır. Bu sayede test pikselinin doğru sınıfa atanma olasıllı̆̆ arttırılmıştır.
\end{abstract}

Anahtar Kelimeler: Hiperspektral, sınıflandırma, seyrek gösterim, adaptif komşuluk seçimi, ă̆ırlık atama

\section{Classification of Hyperspectral Images with Adaptive Neighborhood Selection and Weighting Methods}

\begin{abstract}
Sparse representation based techniques are frequently used in the areas such as signal and image processing, computer vision and pattern recognition due to their performance. In recent years, sparse representation techniques have been used in the proposed methods related to classification of hyperspectral images and favorable results have been obtained. In this article, a joint sparse representation based classifier method that uses adaptive neighborhood selection and weighting processes together is proposed. First, instead of including all of the pixels in the fixed size window created around the test pixel in the classification process, pixels that are close and have similar spectral characteristics to the test pixel are included in the classification. In this way, neighboring pixels which are distant and unlike spectrally to the test pixels are discarded. Then, when determining the class label of the test pixel, the sparse coefficient matrix in the residual value to be calculated is multiplied by the weights determined for each class. Similarity between selected pixels and training dictionary of each class has been considered when the weights are determined. In this way, the probability of assigning the test pixel to the proper class has been increased.
\end{abstract}

Keywords: Hyperspectral, classification, sparse representation, adaptive neighborhood selection, weighting

\footnotetext{
* Sorumlu Yazar
} 


\section{GİRIŞ}

Uzaktan algılama çalışmalarında kullanılan hiperspektral görüntüler birbirlerine yakın olarak konumlandırılmış çok sayıda dalga boyuna sahip sensörler aracılığı ile elde edilir. Yeryüzünde bulunan nesnelerin elektromanyetik dalgaları soğurma ve yansıtma karakteristikleri farklı olmaktadır. Hiperspektral görüntüler de fazla sayıda dalga boyuna sahip oldukları için nesnelerin sınıflandırılması ile ilgili çalışmalarda sıklıkla kullanılmaktadır.

Sinıflandırma ile ilgili yapılan ilk çalışmalarda yalnızca görüntü içerisindeki spektral bilgi kullanılmıştır. (Melgani ve Bruzzone, 2004)'deki çalışmada destek vektör makinaları (Support Vector Machines, SVM) yardımı ile sınıflar arasında hiperdüzlemler oluşturularak test örneklerinin sınıflandırılması sağlanmıştır. (Chen, Nasrabadi ve Tran, 2011) tarafindan yapılan çalışmada seyrek gösterim siniflandırıcı (Sparse Representation Classifier, SRC) modeli önerilmiştir. Buna göre bir test örneği tüm sinıflara ait eğitim örneklerinden oluşan bir eğitim sözlüğü içerisinden yalnızca birkaç eğitim örneği ile temsil edilebilir. (Ma, Crawford ve Tian, 2010) tarafindan önerilen $\mathrm{k}$ en yakın komşuluk ( $\mathrm{K}$ Nearest Neighbor, $\mathrm{KNN}$ ) metodunda ise test örneğine komşu olan en yakın $\mathrm{k}$ adet eğitim örneği seçilip bunların ait olduğu sınıf test örneğinin sınıfı olarak atanmıştır.

Spektral bilgi yardımı ile yapılan çalışmalar sayesinde sınıflandırma sonuçlarında iyi sonuçlar elde edilmiştir fakat yüksek doğruluk değerlerine ulaşılamamıştır. $\mathrm{Bu}$ sebeple literatürde spektral bilgiye ek olarak uzamsal bilginin de sınıflandırma işlemine dahil edilmesi ile yüksek doğruluk değerlerine ulaşan birçok çalışma mevcuttur. Örneğin (Chen ve diğerleri, 2011) her bir test örneği etrafinda oluşturulan sabit boyutlu pencereler yardımı ile piksellerin komşuluk bilgisini yani uzamsal bilgiyi sınıflandırma işlemine dahil eden ortak seyrek gösterim siniflandirıcı (Joint Sparse Representation Classifier, JSRC) modelini geliştirmişlerdir. Bu model teorik olarak SRC modeline benzese de uzamsal bilgi sayesinde sonuçlarda ciddi bir artış görülmüştür. (Camps-Valls, Gomez-Chova, Munoz-Mari, Vila-Frances ve Calpe-
Maravilla, 2006) önerdikleri yöntemde hem spektral hem de uzamsal bilgiyi kullanan çekirdek fonksiyonları SVM yöntemine ekleyerek SVM ile elde edilen sonuçların iyileştirilmesini sağlamışlardır. (Guo, Cao, Han, Sun ve Bai, 2018) ise sabit boyutlu bir pencere içerisindeki pikselleri KNN metodu ile ortak bir şekilde sınıflandırdıktan sonra sonuçlara rehberli filtre (He, Sun ve Tang, 2013) ekleyerek uzamsal bilgiyi eklemiş ve sonuçların iyileştirilmesini sağlamışlardır.

Hiperspektral görüntülerin sinıflandırılması için birçok model önerilmiş olsa da seyrek gösterim tabanlı yaklaşımlar sağladıkları performanstan dolayı araştırmacıların dikkatini daha çok çekmiştir. Örneğin, (Tu ve diğerleri, 2018) çalışmalarında JSRC yönteminde artık değer hesaplanırken test örnekleri ile eğitim örnekleri arasındaki benzerliği korelasyon katsayısı yardımı ile işleme dahil ederek sınıflandırma sonuçlarının doğruluğunda artış sağlamıştır. (L. Gan, J. Xia, P. Du ve Z. Xu, 2017) yaptıkları çalışmada her bir test örneği ile eğitim sözlügündeki atomlar arasındaki farklılık bilgisini bir ağırlı atama yöntemi ile atomlara uygulamıştır. $\mathrm{Bu}$ sayede yerel özellikleri eğitim sözlüğüne eklemiş ve normal SRC yöntemine göre sonuçların doğruluğunda artış sağlamışlardır. (Fang, Li, Kang ve Benediktsson, 2014) ise sabit boyutlu tek bir pencere kullanmak yerine test örneği etrafinda farklı boyutlarda pencereler oluşturarak uzamsal bilginin daha da verimli kullanılmasını sağlamışlardır. (Zhang, Li, Huang ve Zhang, 2014) tarafindan pencere içerisindeki komşu piksellerin ağırlık oranlarının aynı olmadığı düşüncesiyle test örneği etrafındaki her bir komşu piksele yerel olmayan ağırlık atamasının yapıldığı bir yöntem önerilmiştir. (Fang, Li, Kang ve Benediktsson, 2015) tarafindan sabit boyutlu pencere kullanmak yerine görüntü içerisindeki uzamsal bilgiye göre adaptif olarak şekil ve boyut değiştiren süperpiksel bölütleme yöntemi kullanılmıştır. Daha sonra oluşturulan süperpikseller JSRC yöntemine benzer biçimde sınıflandırılmıştır. (Dundar ve Ince, 2018) tarafından yapılan çalışmada test pikseli etrafinda farklı boyutlarda süperpikseller oluşturularak ortak seyrek bir biçimde sınıflandırılmış ve oluşan sinıflandırma haritalarına rehberli filtre 
uygulanarak varolan sonuçların daha da iyileştirilmesi sağlanmıştır.

$\mathrm{Bu}$ makalede önerilen yöntem iki temel aşamadan oluşmaktadır. İlk aşamada test pikseli etrafinda oluşturulan sabit boyutlu bir pencere içerisindeki komşu pikseller her bir test pikseli için adaptif bir biçimde seçilmiştir. Daha sonra oluşturulan piksel grupları için seyrek katsayı matrisi çözülmüştür. Önceden oluşturulan piksel gruplarının ortalama değeri hesaplanarak matris vektör haline getirilir. Ayrıca eğitim sözlüğü içerisinden aynı sınıfa ait olan eğitim örneklerinin de ortalamas1 alınarak bir vektör haline dönüştürülür. Piksel gruplarından elde edilen vektör ile eğitim örneklerinden elde edilen vektörler arasında bir ağırlık hesaplaması yapılır. İkinci aşamada ise test örneğinin sınıf etiketini belirlerken hesaplanan artık değerde seyrek katsayı matrisinin ilgili satırları bu ağırlıklarla çarpılmıştır.

\section{YÖNTEM}

$\mathrm{Bu}$ bölümde SRC ve JSRC yöntemlerinin teorik altyapısı anlatılmıştır. Bunlara ek olarak JSRC metoduna komşuluk seçimi ve ağırlı atama yöntemleri ayrı ayrı uygulanmıştır. Son olarak ise önerilen yönteme ait teorik çalışmalar oluşturulmuştur.

Eğitim sözlüğü matrisi $\mathbf{D}=\left[\begin{array}{llll}\mathbf{D}_{1} & \mathbf{D}_{2} & \cdots & \mathbf{D}_{C}\end{array}\right] \in \square^{B \times N}$ veriden rastgele seçilerek oluşturulmuştur. Sınıflara ait her bir alt eğitim sözlüğü ise $\mathbf{D}_{i}=\left[\begin{array}{llll}\mathbf{D}_{i_{1}} & \mathbf{D}_{i_{2}} & \cdots \mathbf{D}_{i_{N_{i}}}\end{array}\right] \in \square^{B \times N_{i}} \quad(i=1,2, \cdots, C)$ matrisi ile gösterilmiştir. $B$ görüntü içerisindeki toplam bant sayısını, $N$ toplam eğitim örneği sayısını ve $C$ ise veri setindeki toplam sınıf sayısını belirtmektedir.

\subsection{Seyrek Gösterim Sinıflandırıcısı}

$\mathrm{Bu}$ yöntemde bir test pikselinin eğitim sözlüğü içerisinden yalnızca birkaç adet örnek ile seyrek bir şekilde temsil edilebileceği önerilmiştir. Bu eşitlik

$$
\mathbf{y}=\mathbf{D} \boldsymbol{\alpha}
$$

şeklinde gösterilebilir. $\mathrm{Bu}$ denklemde $\boldsymbol{\alpha}$ seyrek katsayı vektörünü temsil etmektedir.
Eğer bu denkleme hata payı veya görüntü içerisinde olabilecek gürültüler eklenecek olursa

$\mathbf{y}=\mathbf{D} \boldsymbol{\alpha}+\boldsymbol{\varepsilon}$

(2)'deki gibi denklem elde edilir. Hata payını minimize etmek için ve aynı zamanda da seyreklik koşulunu sağlamak için

$\hat{\boldsymbol{\alpha}}=\arg \min \|\mathbf{y}-\mathbf{D} \boldsymbol{\alpha}\|_{2} \quad$ oyle ki $\quad\|\boldsymbol{\alpha}\|_{0} \leq S$

(3)'teki optimizasyon problemi seyrek katsayı vektörü için çözülmelidir. Burada $S$ vektörün seyreklik seviyesidir ve $\|\cdot\|_{0}$ ise $\mathrm{L}_{0}$ normu ifade eder ve vektör içerisinde sıfır olmayan elemanları sayar. $\mathrm{Bu}$ problemin çözümü için literatürdeki Dik Eşleştirme Arayış (DEA) (Tropp ve Gilbert, 2007) optimizasyon algoritmas1 kullanılabilir. Seyrek katsayı vektörü $\hat{\boldsymbol{\alpha}}$ bulunduktan sonra artık değer $\mathbf{r}$

$\mathbf{r}_{i}=\left\|\mathbf{y}-\mathbf{D}_{i} \hat{\boldsymbol{\alpha}}_{i}\right\|_{2} \quad$ öyleki $i=1,2, \cdots, C$

her bir sınıf için denklem (4)'teki gibi hesaplanır. Test pikseli $\mathbf{y}$ 'nin sınıfi ise en düşük artık değere sahip sınıf olarak belirlenir.

$\operatorname{Sinlf}(\mathbf{y})=\arg \min \left(\mathbf{r}_{i}\right)$

\subsection{Ortak Seyrek Gösterim Sinıflandırıcısı}

$\mathrm{Bu}$ yöntemde ise tek bir test pikseli yerine merkezde test pikseli olmak koşuluyla sabit boyutlu bir kare pencere oluşturulur. $\mathrm{Bu}$ sayede görüntü içerisindeki uzamsal bilgi de sinıflandırmaya dahil edilmiş olur. Test örneği ve etrafındaki komşu pikselleri içeren $\mathbf{P}$ matrisi

$$
\mathbf{P}=\left[\mathbf{p}_{1} \mathbf{p}_{2} \cdots \mathbf{p}_{Q}\right]
$$

oluşturulur. Burada $\mathbf{p}_{1}$ merkezdeki test pikselini ve $Q$ ise pencere içerisindeki toplam piksel sayısını ifade eder. SRC yönteminde olduğu gibi amaç seyrek katsayı matrisini bulmak olduğu için (3)'teki problem

$$
\hat{\mathbf{A}}=\arg \min \|\mathbf{P}-\mathbf{D A}\|_{F} \quad \text { öyle ki } \quad\|\mathbf{A}\|_{0} \leq S
$$

JSRC yöntemi için denklem (7)'deki gibi yazılabilir. Burada $\|\cdot\|_{F}$ ise Frobenius normu temsil etmektedir. Bu problemin çözümü için 
literatürdeki Eşzamanlı Dik Eşleştirme Arayış (EDEA) (Tropp, Gilbert ve Strauss, 2006) optimizasyon algoritmas1 kullanılabilir. Seyrek katsayı matrisi $\hat{\mathbf{A}}$ bulunduktan sonra artık değer $\mathbf{R}$ her bir sınıf için hesaplanır.

$\mathbf{R}_{i}=\arg \min \left\|\mathbf{P}-\mathbf{D}_{i} \hat{\mathbf{A}}_{i}\right\|_{F}$

$\mathbf{p}_{1}$ test pikselinin sinıfi ise minimum artık değere sahip sınıf olarak belirlenir.

$\operatorname{Sinlf}\left(\mathbf{p}_{1}\right)=\arg \min \left(\mathbf{R}_{i}\right)$

\subsection{Adaptif Komşuluk Seçim Yöntemi}

JSRC metodunda sabit boyutlu pencere içerisindeki merkezde bulunan test pikseli ve etrafindaki piksellerin spektral karakteristiklerinin aynı olduğu varsayılarak sınıflandırma işlemi yapılır. $\mathrm{Bu}$ yaklaşım küçük boyutlu pencereler için kısmen doğru olsa da özellikle büyük boyutlu pencerelerde yanlış sınıflandırmalara sebep olabilmektedir. Çünkü bu durumda farklı sinıflara ait pikseller de sınıflandırma işlemine dahil edilmektedir. Komşuluk seçim yöntemi sayesinde pencere içerisindeki benzer spektral karakteristiğe sahip pikseller gruplandırılarak sınıflandırma başarı oranları arttırılabilir. Bu doğrultuda (L. Pan, H. Li ve X. Chen, 2016; Q. Wang, X. He ve $X$. Li, 2018) çalışmalarında uygulanan benzerlik yöntemi JSRC metoduna da uygulanmıştır. İlk olarak $\mathbf{P}$ matrisi içerisindeki $\mathbf{p}_{1}$ test örneği ile diğer pikseller arasındaki mesafe bahsi geçen benzerlik yöntemi ile hesaplanarak $M$ vektörü oluşturulur.

$$
\begin{gathered}
M_{1, j}=\sqrt{\left\|\mathbf{p}_{1}-\mathbf{p}_{j}\right\|_{2}^{2}+\left\|k_{1}-k_{j}\right\|_{2}^{2}} \\
\text { oyle } k i \quad j=2,3, \cdots, Q
\end{gathered}
$$

Denklem (10)'da $k_{1}$ test örneğinin görüntü içerisindeki koordinatlarını ve $k_{j}$ ise sırasıyla diğer piksellerin koordinatlarını belirtmektedir ve bu değerler [0 1 1] arasinda normalize edilmelidir. Yani bu denklem sayesinde hem test örneği ile herhangi bir piksel arasındaki uzaklik bulunur hem de koordinat bilgileri kullanılmış olur. $M$ vektörü oluşturulduktan sonra standart sapması (11) numaralı denklem yardımı ile aşağıdaki gibi hesaplanır.

$$
\begin{aligned}
\sigma_{M} & =\sqrt{\frac{1}{Q-1} \sum_{j=2}^{Q}\left(M_{1, j}-\mu_{M}\right)^{2}} \\
\mu_{M} & =\frac{1}{Q-1} \sum_{j=2}^{Q} M_{1, j}
\end{aligned}
$$

Burada $\mu_{M}$ değeri $M$ vektörünün ortalama değerini göstermektedir. Standart sapma değeri hesaplandıktan sonra eşik değeri $\mathbf{E}$

$\mathbf{E}=\beta \times \sigma_{M}$

belirlenir. Denklem (12)'de $\beta$ değeri bir parametredir ve standart sapma değerine göre eşik değerini belirler. E değeri belirlendikten sonra $M$ vektöründe bu değerden küçük veya eşit olan değerler ve bunların indeks değerleri belirlenir.

[Değer İndeks $] \leftarrow M_{1, j} \leq \mathbf{E}$

Seçilen indeksler sayesinde de $\mathbf{P}$ matrisi içerisinden ilgili indeksler seçilerek $\mathbf{p}_{1}$ test örneğini ve benzer spektral karakteristiğe sahip pikselleri içeren $\tilde{\mathbf{P}}$ matrisi oluşturulur.

$\tilde{\mathbf{P}}=\left[\mathbf{p}_{1} \cdots \mathbf{p}_{x}\right]$

$\mathrm{Bu}$ aşamadan sonra ise $\tilde{\mathbf{P}}$ matrisi için sırasıyla (7), (8) ve (9) numaralı denklemler çözülür ve $\mathbf{p}_{1}$ test örneğinin sınıfı bulunur.

$\mathrm{Bu}$ yöntemin makale içerisindeki kısaltması OSGS-AK olarak kullanılacaktır.

\subsection{Ağırlık Atama Yöntemi}

JSRC metodunda seyrek katsay1 matrisi belirlendikten sonra artık değer hesaplanarak pikselin sınıfı belirlenmektedir. Ĕger bu aşamada pencere içerisindeki pikseller ile eğitim pikselleri arasındaki benzerlikler artık değer hesaplamasına dahil edilebilirse sınıflandırma sonuçlarında artış gözlemlenebilir. Bunun için ilk olarak $\mathbf{P}$ matrisinin ortalaması (15) numaralı denklem yardımı ile bulunur.

$\overline{\mathbf{P}}=\frac{1}{Q} \sum_{j=1}^{Q} \mathbf{p}_{j}$

Daha sonra her bir alt eğitim sözlüğünün aynı şekilde ortalaması (16) numaralı denklem yardımı ile hesaplanır. 


$$
\overline{\mathbf{D}}_{i}=\frac{1}{N_{i}} \sum_{n=1}^{N_{i}} \mathbf{D}_{i_{n}}
$$

$\overline{\mathbf{P}}$ ile $\overline{\mathbf{D}}_{i}$ arasındaki benzerlik ise aşağıdaki denklem yardımı ile hesaplanmıştır.

$$
W_{i}=\operatorname{kor}\left(\overline{\mathbf{P}}, \overline{\mathbf{D}}_{i}\right) \times e^{\left(-\left\|\overline{\mathbf{P}}-\overline{\mathbf{D}}_{i}\right\|_{2}\right)}
$$

Denklem (17)'de kor korelasyon katsayısını temsil etmektedir. $\mathrm{Bu}$ değer birbirine benzeyen iki vektör için 1'e yakın olurken, birbiri ile benzemeyen iki vektör için 0 'a yakın olmaktadır. Her bir sınıf için $W_{i}$ değeri bulunduktan sonra artık değer hesabına aşağıdaki gibi eklenmelidir.

$$
\mathbf{R}_{i}=\left\|\mathbf{P}-\mathbf{D}_{i}\left(W_{i}^{2} \times \hat{\mathbf{A}}_{i}\right)\right\|_{F}
$$

Denklem (18)'de farklı sınıflara ait ağırlık oranları arasındaki fark1 biraz daha arttırabilmek için $W_{i}$ değerinin karesi alınmıştır.

$\mathrm{Bu}$ yöntemin makale içerisindeki kısaltması OSGS-AA olarak kullanılacaktır.

\section{5. Önerilen Yöntem}

$\mathrm{Bu}$ makalede önerilen yöntem hem adaptif komşuluk seçim yöntemini hem de ağırlık atama yöntemini aynı anda kullanan OSGSAKAA metodudur.

İlk olarak OSGS-AK yönteminde kullanılan (10), (11), (12) ve (13) numaral denklemler vasıtası ile test örneğinin komşulukları belirlenerek (14)'deki gibi $\tilde{\mathbf{P}}$ matrisi oluşturulur. Daha sonra OSGS-AA yöntemindeki (15), (16) ve (17) numaralı denklemler yardımı ile ağırlıklar belirlenir. Artık değer ise

$$
\mathbf{R}_{i}=\left\|\tilde{\mathbf{P}}-\mathbf{D}_{i}\left(W_{i}^{2} \times \hat{\mathbf{A}}_{i}\right)\right\|_{F}
$$

denklem (19) yardımı ile belirlenir ve daha sonra minimum artık değere sahip sınıfa göre test örneğinin sınıfı belirlenir.

Önerilen OSGS-AKAA yöntemine ait algoritma örneği yan sütunda bulunmaktadır.

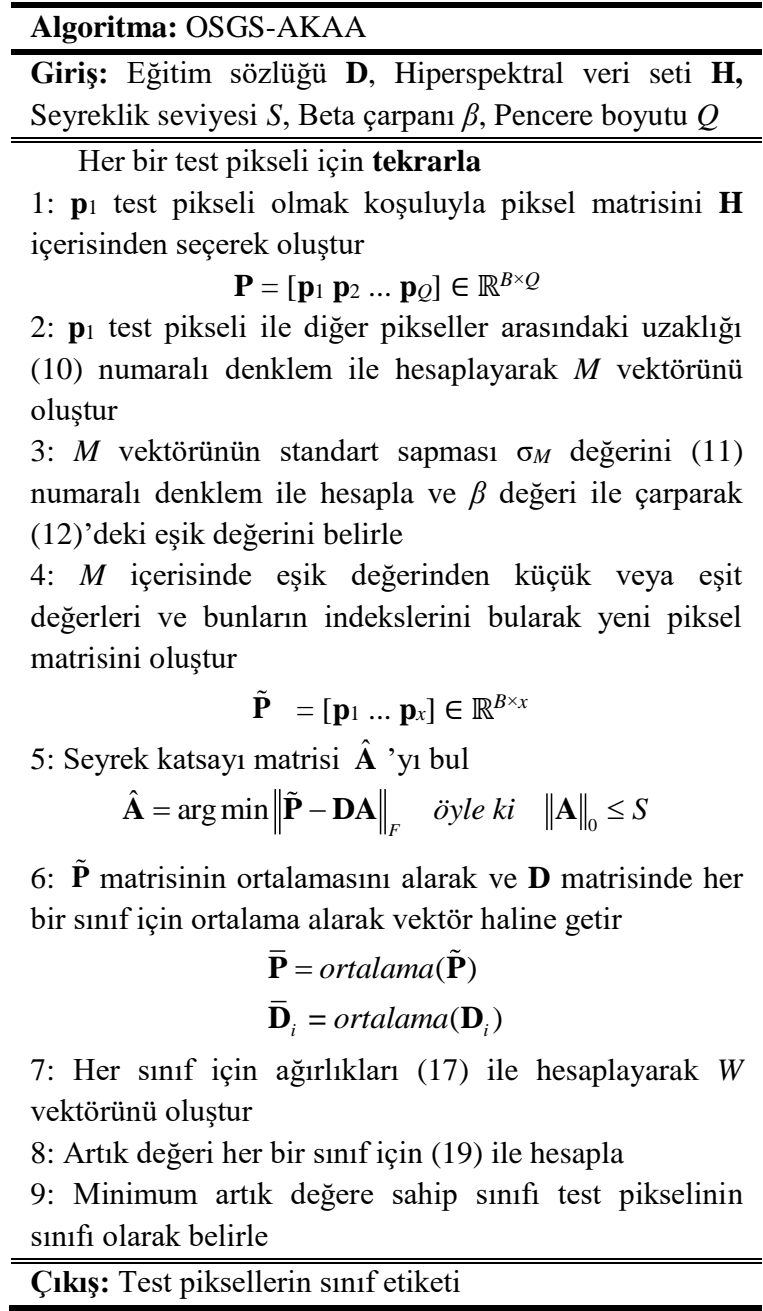

\section{BULGULAR}

\subsection{Veri Seti}

$\mathrm{Bu}$ çalışmada hiperspektral sinıflandırma alanında sıklıkla üzerinde çalışılan ve AVIRIS sensörü tarafindan elde edilen Indian Pines veri seti kullanılmıştır ("AVIRIS NW Indiana's Indian Pines Data Set", 1992). Sensörün spektral aralığı $0.4-2.4 \mu \mathrm{m}$ ve piksel başına mekansal çözünürlüğü ise 20 metredir. Veri seti $145 \times 145$ boyutunda olup 220 adet spektral banttan oluşmaktadır ve çevrimiçi olarak temin edilebilmektedir. Fakat su emilimi ve atmosferik koşullardan kaynaklı olumsuz etkenler sebebiyle bazı bantlar [104108, 150-163, 220] veri setinden çıkartılmıştır (J. Anthony Gualtieri ve Robert F. Cromp, 1999). Dolayısiyla veri seti son olarak $145 \times 145 \times 200$ boyutlu bir hale getirilmiştir. Çoğunlukla tarımsal ürünlerden oluşan 16 farklı sınıfa sahiptir. Sinıflara ait bilgiler ve sinıflarda bulunan örnek sayıları Tablo 1'de 
sunulmuştur. Ayrica veri setine ait yer gerçekliği haritası da Şekil 1'de bulunmaktadir.

Tablo 1. Indian Pines Veri Setine Ait Sınıf Bilgileri ve Örnek Sayıları

\begin{tabular}{ccc}
\hline Sinıf & $\begin{array}{c}\text { Sinıf adı (Chen ve diğerleri, } \\
\text { 2011) }\end{array}$ & $\begin{array}{c}\text { Örnek } \\
\text { sayls1 }\end{array}$ \\
\hline 1 & Alfalfa & 54 \\
2 & Corn-notill & 1434 \\
3 & Corn-min & 834 \\
4 & Corn & 234 \\
5 & Grass/Pasture & 497 \\
6 & Grass/Trees & 747 \\
7 & Grass/Pasture-mowed & 26 \\
8 & Hay-windrowed & 489 \\
9 & Oats & 20 \\
10 & Soybean-notill & 968 \\
11 & Soybean-min & 2468 \\
12 & Soybean-clean & 614 \\
13 & Wheats & 212 \\
14 & Woods & 1294 \\
15 & Building-Grass-Tree-Drives & 380 \\
16 & Stone-steel Towers & 95 \\
\hline \multicolumn{3}{c}{ Toplam } \\
\hline
\end{tabular}

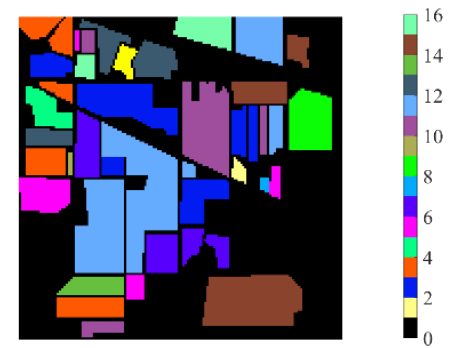

Şekil 1. Indian Pines Görüntüsüne Ait Yer Gerçekliği Haritasi ve Sınıf Etiketleri

\subsection{Hesaplama Metrikleri}

Hiperspektral görüntülerin siniflandırılması ile ilgili yapılan çalıșmaların sonuç karşılaştırması kısmında bazı metrikler bulunmaktadır. Bunlar sirasiyla genel doğruluk (GD), sınıf doğrulukları (SD), ortalama doğruluk (OD) ve kappa $(K)$ değeridir. Bu metriklere ait formüller sırasıyla aşağıda bulunmaktadır.

$$
\begin{aligned}
& \mathrm{GD}=\frac{\text { Doğru sınıflandırılan test örneği sayıSı }}{\text { Toplam test örneği sayısı }} \\
& \mathrm{SD}=\frac{\text { İlgili sınıfa doğru atanan test örneği sayısı }}{\text { İlgili sınıfa ait toplam test örneği sayısı }}
\end{aligned}
$$

$$
\begin{aligned}
& \mathrm{OD}=\frac{\text { Sınıf doğruluk değerlerinin toplamı }}{\text { Toplamsınıf sayısı }} \\
& K=\frac{(\text { Gözlemlenen değer- Beklenen değer })}{(1-\text { Beklenen değer })}
\end{aligned}
$$

\subsection{Parametre Ayarlaması}

Önerilen OSGS-AKAA metodu literatürdeki SVM (Melgani ve Bruzzone, 2004), SVM-CK (Camps-Valls ve diğerleri, 2006), SRC (Chen ve diğerleri, 2011), WSRC (Lu, Min, Gui, Zhu ve Lei, 2013) ve JSRC (Chen ve diğerleri, 2011) metotları ile karşılaştırılmıştır. Ayrıca JSRC metoduna yalnızca adaptif komşuluk seçim yönteminin eklendiği OSGS-AK metodu ve yine JSRC metoduna yalnızca ağırlık atama yönteminin eklendiği OSGS-AA metotları ile de karşılaştırılmıştır.

SVM metodunda gauss radyal temel fonksiyonu kullanılmış olup en uygun parametrelerin seçilmesi için 5-kat çapraz doğrulama yapılmıştır. SVM-CK metodunda $9 \times 9$ pencere boyutu kullanılmıştır ve diğer parametreler makaleden alınmıştır. SRC yönteminde önerildiği gibi seyreklik seviyesi 5 olarak seçilmiştir. JSRC yönteminde önerilen $9 \times 9$ pencere boyutu ve seyreklik seviyesi olarak da 30 değeri kullanılmıştır. WSRC yönteminde ağırlıklı $\mathrm{L}_{1}$ minimizasyon yüz tanıma sistemi için önerilmiştir. $\mathrm{Bu}$ çalışmada ise parametreler tekrar ayarlanarak Indian Pines hiperspektral veri seti için uygulanmıştır.

Önerilen OSGS-AKAA yöntemi için $9 \times 9$ pencere boyutu seçilerek yöntem bunun üzerinde uygulanmıştır. Farklı seyreklik seviyeleri ve beta değerleri kullanılarak GD ve OD değerleri sırasıyla Şekil 2'de gösterilmiştir. Şekillerden de görüleceği üzere seyreklik seviyesi $S=5$ ve $\beta=2$ değerleri için hem GD değeri hem de OD değeri maksimum seviyededir. OSGS-AK yöntemi için de seyreklik seviyesi olarak $S=5$, beta değeri için $\beta=2$ ve $9 \times 9$ pencere boyutu kullanılmıştır. OSGS-AA yönteminde ise seyreklik seviyesi olarak $S=30$ değeri ve $9 \times 9$ pencere boyutu kullanılmıştır. 


\subsection{Deneysel Analiz}

Sınıflara ait eğitim ve test örneği sayıları ile sınıflandırma sonuçlarına ilişkin bilgiler Tablo 2'de sunulmuştur. Görüleceği üzere görüntüdeki uzamsal bilgileri kullanmayan SVM, SRC ve WSRC yöntemleri yerel bilgilerin kullanıldığı diğer metotlara göre daha düşük performans sergilemişlerdir. WSRC yönteminde SRC yöntemine ek olarak ağırlıklar da eklendiği için hem genel hem ortalama hem de kappa değeri bakımından daha iyi sonuçlar elde edilmiştir. SVM-CK yöntemi görüntüdeki uzamsal bilgiyi de kullandığı için SVM yöntemine göre çok daha iyi sonuçlar sağlamıştır. JSRC yöntemine adaptif komşuluk seçimi eklenmesiyle elde edilen OSGS-AK metodunun daha üstün geldiği görülmektedir. Çünkü pencere içerisindeki farklı spektral karakteristiğe sahip pikseller seçim yöntemi sayesinde sınıflandırma işlemine dahil edilmemiştir. Ayrıca JSRC yöntemine ağırlık atama eklenmesiyle OSGS-AA metodu da sonuçları az da olsa arttırmıştır fakat bu artış OSGS-AK metodundaki kadar olmamaktadır. Çünkü OSGS-AA yönteminde herhangi bir komşuluk seçimi uygulanmamıştır. Dolayısıyla farklı spektral yapıya sahip pikseller de sinıflandırma işlemine dahil edilmiştir. Önerilen OSGS-AKAA metodunda yani hem komşuluk seçiminin hem de ağırlık atamanın olduğu durumda GD, OD ve $K$ değerleri diğer tüm metotlara kıyasla daha üstün gelmektedir. Eğer sonuçlar dikkatli bir şekilde gözlemlenecek olursa OSGS-AKAA ile OSGS-AK arasında ciddi bir fark bulunmamaktadır. Fakat yine de ağırlık oranlarının da eklenmesiyle sonuçlar OSGSAK metoduna göre biraz daha iyileştirilmiştir.

Metotlara ait sinıflandırma haritaları sırasıyla Şekil 3'de sunulmuştur. Görüleceği üzere görüntü içerisindeki uzamsal bilginin kullanılmadığ1 SVM, SRC ve WSRC yöntemlerinde sonuçlar oldukça gürültülüdür. Uzamsal bilgini kullanıldığı SVM-CK, JSRC, OSGS-AK, OSGS-AA ve OSGS-AKAA yöntemlerinde ise gürültü çok fazla değildir.

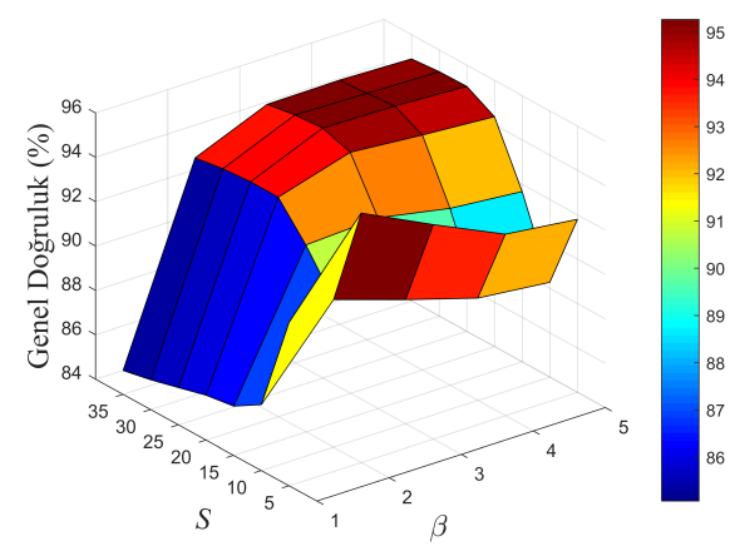

(a)

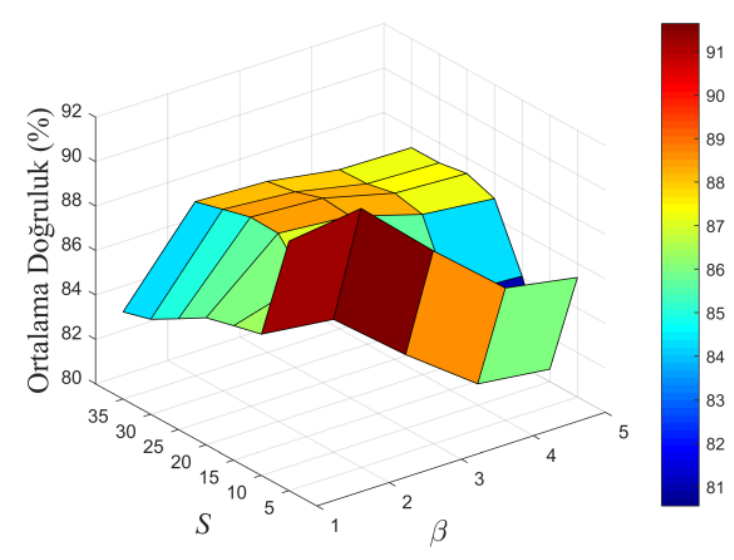

(b)

Şekil 2. Önerilen OSGS-AKAA Metodunda Seyreklik Seviyesi $S$ ve $\beta$ Parametrelerinin; (a) Genel Doğruluk, (b) Ortalama Doğruluk Sonuçlarına Etkisi 
Tablo 2. Indian Pines Veri Setinde SVM, SVM-CK, SRC, WSRC, JSRC, OSGS-AK, OSGS-AA ve OSGS-AKAA Metotları ile Elde Edilen Sınıflandırma Doğruluk Değerleri

\begin{tabular}{ccccccccccc}
\hline Sinıf & Eğitim & Test & SVM & SVM-CK & SRC & WSRC & JSRC & OSGS-AK & OSGS-AA & OSGS-AKAA \\
\hline 1 & 6 & 48 & 75,00 & 88,13 & 64,38 & 66,25 & 88,13 & $\mathbf{9 4 , 5 8}$ & 87,08 & $\mathbf{9 4 , 5 8}$ \\
2 & 144 & 1290 & 81,36 & 92,29 & 65,24 & 68,28 & 93,47 & 93,22 & $\mathbf{9 3 , 8 9}$ & 93,29 \\
3 & 84 & 750 & 75,75 & $\mathbf{9 4 , 8 0}$ & 61,27 & 65,35 & 93,43 & 94,40 & 93,73 & 94,61 \\
4 & 24 & 210 & 72,76 & 88,10 & 46,05 & 50,95 & 92,43 & 89,52 & $\mathbf{9 3 , 3 3}$ & 89,57 \\
5 & 50 & 447 & 93,00 & $\mathbf{9 4 , 0 0}$ & 89,44 & 90,27 & 93,47 & 93,06 & 92,62 & 93,00 \\
6 & 75 & 672 & 96,00 & 98,39 & 94,72 & 95,22 & 99,18 & 98,15 & $\mathbf{9 9 , 1 8}$ & 98,15 \\
7 & 3 & 23 & 72,61 & 80,00 & 79,13 & 77,83 & 54,35 & $\mathbf{8 1 , 7 4}$ & 60,00 & $\mathbf{8 1 , 7 4}$ \\
8 & 49 & 440 & 98,23 & 97,98 & 97,61 & 98,11 & 99,86 & 99,64 & $\mathbf{9 9 , 8 9}$ & 99,64 \\
9 & 2 & 18 & 78,33 & $\mathbf{8 6 , 1 1}$ & 51,67 & 62,78 & 7,78 & 64,44 & 7,78 & 64,44 \\
10 & 97 & 871 & 72,38 & 88,69 & 71,81 & 75,21 & 87,80 & 91,93 & 87,90 & $\mathbf{9 1 , 9 5}$ \\
11 & 247 & 2221 & 84,32 & 93,53 & 76,09 & 78,93 & 97,43 & 96,21 & $\mathbf{9 7 , 7 1}$ & 96,27 \\
12 & 62 & 552 & 86,27 & $\mathbf{9 3 , 7 7}$ & 56,20 & 61,30 & 87,70 & 91,27 & 88,84 & 91,34 \\
13 & 22 & 190 & 99,42 & $\mathbf{9 9 , 4 7}$ & 97,89 & 98,11 & 99,16 & 98,16 & 99,37 & 98,16 \\
14 & 130 & 1164 & 96,19 & 96,16 & 94,03 & 95,17 & 99,41 & $\mathbf{9 9 , 7 3}$ & 99,15 & $\mathbf{9 9 , 7 3}$ \\
15 & 38 & 342 & 59,50 & 84,24 & 41,84 & 47,98 & 97,02 & 93,22 & $\mathbf{9 7 , 3 4}$ & 93,74 \\
16 & 10 & 85 & 92,24 & $\mathbf{9 7 , 1 8}$ & 92,71 & 92,00 & 94,24 & 95,76 & 92,71 & 95,76 \\
\hline GD & - & - & 84,74 & 93,55 & 75,62 & 78,27 & 94,93 & 95,22 & 95,12 & $\mathbf{9 5 , 2 8}$ \\
OD & - & - & 83,33 & 92,05 & 73,75 & 76,48 & 86,55 & 92,19 & 86,91 & $\mathbf{9 2 , 2 5}$ \\
$K$ & - & - & 82,59 & 92,65 & 72,17 & 75,20 & 94,22 & 94,55 & 94,43 & $\mathbf{9 4 , 6 2}$ \\
\hline
\end{tabular}

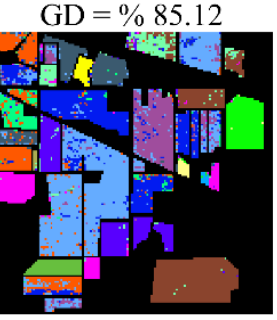

(a)

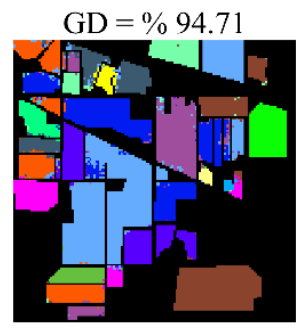

(e)

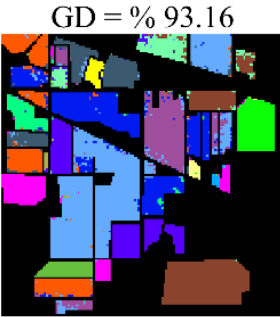

(b)

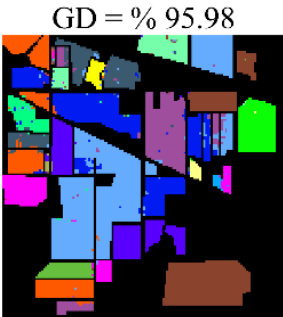

(f)

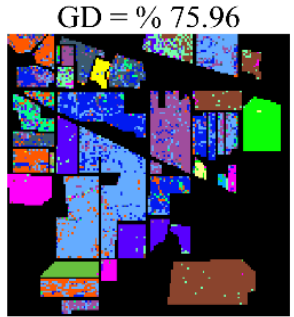

(c)

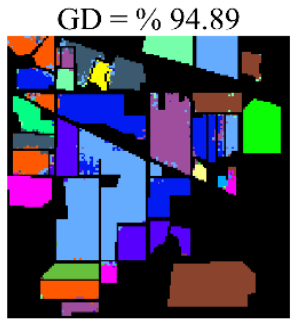

(g)

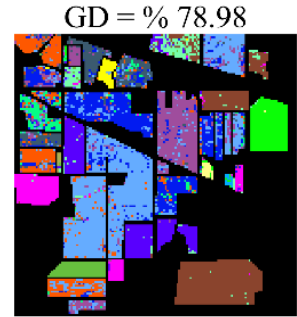

(d)

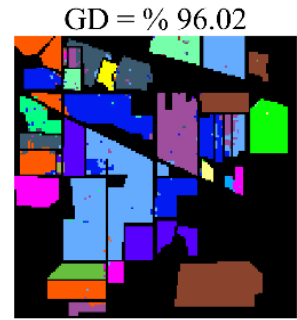

(h)

Şekil 3. Indian Pines Görüntüsüne Ait Sınıflandırma Haritaları; (a) SVM, (b) SVM-CK, (c) SRC, (d) WSRC, (e) JSRC, (f) OSGS-AK, (g) OSGS-AA, (h) OSGS-AKAA 


\section{SONUÇLAR ve TARTIŞMA}

$\mathrm{Bu}$ makalede hiperspektral görüntülerin sınıflandırılması için adaptif komşuluk seçimi ve ağırlı atama yöntemlerini ortaklaşa kullanan OSGS-AKAA metodu önerilmiştir. Adaptif komşuluk seçimi ile pencere içerisinde yalnızca test örneğine benzeyen pikseller seçilmiştir. Ağırlık atama yöntemi ile de artık değer hesabında seyrek katsayı matrisine seçilen pikseller ile sınıflara ait eğitim örnekleri arasındaki benzerlik oranları bir ağırlık olarak atanmıştır. Analizler bir hiperspektral veri seti üzerinde yapılmıştır ve önerilen metodun literatürde bulunan bazı yöntemlere göre daha iyi sonuçlar verdiği gözlemlenmiştir.

Farklı bir yöntemle komşulukların adaptif olarak seçilmesi veya farklı bir ağırlık atama yönteminin uygulanması halinde sonuçlar daha da iyileştirilebilir. Ek olarak eğitim sözlüğünü veri seti içerisinden rastgele seçmek yerine etkili bir eğitme algoritmasının kullanılması ile oluşturulabilecek eğitim sözlügü ile daha iyi sonuçlar sağlayabilir.

\section{TEŞEKKÜR}

$\mathrm{Bu}$ çalışma TÜBİTAK 215E179 numaralı proje kapsamında yapılmıștır. Bizlere sağladığ 1 desteklerden dolayı TÜBİTAK'a teşekkür ederiz.

\section{KAYNAKÇA}

AVIRIS NW Indiana's Indian Pines Data Set. (1992).

https://engineering.purdue.edu/ biehl/Multi Spec/hyperspectral.html adresinden erişildi.

Camps-Valls, G., Gomez-Chova, L., Munoz-Mari, J., Vila-Frances, J. ve Calpe-Maravilla, J. (2006). Composite Kernels for Hyperspectral Image Classification. IEEE Geoscience and Remote Sensing Letters, 3(1), 93-97.

Chen, Y., Nasrabadi, N. M. ve Tran, T. D. (2011). Hyperspectral Image Classification Using Dictionary-Based Sparse Representation. IEEE Transactions on Geoscience and Remote Sensing, 49(10), 3973-3985.

Dundar, T. ve Ince, T. (2018). Sparse Representation-Based Hyperspectral Image Classification Using Multiscale Superpixels and Guided Filter. IEEE Geoscience and Remote Sensing Letters, 1-5.
Fang, L., Li, S., Kang, X. ve Benediktsson, J. A. (2014). Spectral-Spatial Hyperspectral Image Classification via Multiscale Adaptive Sparse Representation. IEEE Transactions on Geoscience and Remote Sensing, 52(12), 7738-7749.

Fang, L., Li, S., Kang, X. ve Benediktsson, J. A. (2015). Spectral-Spatial Classification of Hyperspectral Images With a SuperpixelBased Discriminative Sparse Model. IEEE Transactions on Geoscience and Remote Sensing, 53(8), 4186-4201.

Guo, Y., Cao, H., Han, S., Sun, Y. ve Bai, Y. (2018). Spectral-Spatial HyperspectralImage Classification With KNearest Neighbor and Guided Filter. IEEE Access, 6, 18582-18591.

He, K., Sun, J. ve Tang, X. (2013). Guided Image Filtering. IEEE Transactions on Pattern Analysis and Machine Intelligence, 35(6), 1397-1409.

J. Anthony Gualtieri ve Robert F. Cromp. (1999). Support vector machines for hyperspectral remote sensing classification. Proc. SPIE içinde (C. 3584, ss. 221-232).

L. Gan, J. Xia, P. Du ve Z. Xu. (2017). Dissimilarity-Weighted Sparse Representation for Hyperspectral Image Classification. IEEE Geoscience and Remote Sensing Letters, 14(11), 19681972.

L. Pan, H. Li ve X. Chen. (2016). Locality constrained low-rank representation for hyperspectral image classification. 2016 IEEE International Geoscience and Remote Sensing Symposium (IGARSS) içinde (ss. 493-496).

Lu, C.-Y., Min, H., Gui, J., Zhu, L. ve Lei, Y.-K. (2013). Face recognition via Weighted Sparse Representation. Journal of Visual Communication and Image Representation, 24(2), 111-116.

Ma, L., Crawford, M. M. ve Tian, J. (2010). Local Manifold Learning-Based -NearestNeighbor for Hyperspectral Image Classification. IEEE Transactions on Geoscience and Remote Sensing, 48(11), 4099-4109.

Melgani, F. ve Bruzzone, L. (2004). Classification of hyperspectral remote sensing images with support vector machines. IEEE Transactions on Geoscience and Remote Sensing, 42(8), 1778-1790.

Q. Wang, X. He ve X. Li. (2018). Locality and Structure Regularized Low Rank Representation for Hyperspectral Image Classification. IEEE Transactions on Geoscience and Remote Sensing, 1-13.

Tropp, J. A. ve Gilbert, A. C. (2007). Signal Recovery From Random Measurements 
Via Orthogonal Matching Pursuit. IEEE Transactions on Information Theory, 53(12), 4655-4666.

Tropp, J. A., Gilbert, A. C. ve Strauss, M. J. (2006). Algorithms for simultaneous sparse approximation. Part I: Greedy pursuit. Signal Processing, 86(3), 572-588.

Tu, B., Zhang, X., Kang, X., Zhang, G., Wang, J. ve $\mathrm{Wu}$, J. (2018). Hyperspectral Image Classification via Fusing Correlation Coefficient and Joint Sparse Representation. IEEE Geoscience and Remote Sensing Letters, 15(3), 340-344.

Zhang, H., Li, J., Huang, Y. ve Zhang, L. (2014). A Nonlocal Weighted Joint Sparse Representation Classification Method for Hyperspectral Imagery. IEEE Journal of Selected Topics in Applied Earth Observations and Remote Sensing, 7(6), 2056-2065. 